\title{
WORLD ORGANIZATION OF VOLCANO OBSERVATORIES
}

by

Gudmundur E. Sigvaldason

The past decade has been unusually eventful for the science of volcanology. Many volcanic eruptions occurred, some of which posed considerable hazard to populated areas. In the past 20 years volcanic eruptions have claimed at least 3000 lives. In response to government, scientific and popular concern, a new organization, the World Organization of Volcano Observatories, has been established to monitor volcanoes and to provide an early warning system for residents of populated areas.

\section{Introduction}

The 1973 volcanic eruption on Heimaey, Iceland, which partly destroyed the town of Vestmannaeyjar, stands out because of a massive effort made by the inhabitants to save the town from being destroyed by advancing lava flows.

Rumblings of the Soufriere volcano in April 1979, on Guadeloupe, West Indies, resulted in the evacuation of about 74000 people living on the slopes of the volcano. The "volcanic crisis" created an administrative and scientific dilemma centring on which criteria should be used to judge the situation safe enough to allow the people to return to their homes.

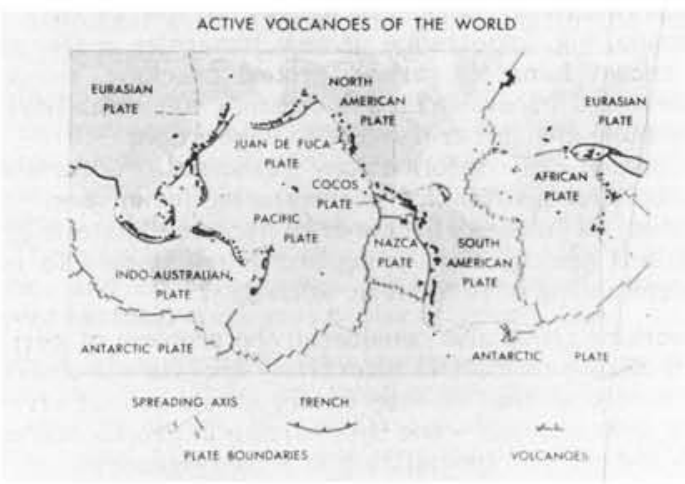

In March 1980, when Mount St. Helens (Washington, U.S.A.) gave the first signs of reawakening, volcanologists worked closely with local authorities to continually assess the volcanic and associated hazards posed by the eruption that began on March 27, 1980. The culmination of an eventful decade in volcanology came on May 18, 1980, when Mount St. Helens erupted, causing considerable destruction and loss of life (see EPISODES Vol. 1980, No. 2, p. 27-29). This eruption will probably go down in history as the best documented volcanic event since the beginning of modern volcanology. The experience gained from this eruption should improve our understanding of explosive eruptions, as well as the interaction between scientists and decision-makers in matters related to volcanic hazards.

The construction of a geothermal power station had just begun in Iceland in 1975 when Krafla volcano showed signs of renewed activity. Volcanologists warned that activity might increase and continue for years, but government officials concluded that volcanological advice was not sufficient to declare a major hazard warning. As partial compensation for a power station without power, Krafla has provided an excellent opportunity to study volcanic and tectonic processes associated with crustal rifting.
In Italy, Etna has created both civil defense problems and opportunities for scientific study, and on Kamchatka, U.S.S.R., volcanologists were able to predict the eruption of Tolbachiek volcano in 1976 on the basis of premonitory seismicity.

\section{West Indies Meeting}

In the examples mentioned above, volcanologists, in addition to being scientists, have had to play an important social role as advisers to administrators. In many cases, they were poorly prepared, partly because of the low priority volcanology has been given in scientific research funding allocations, and partly because they were faced with new situations never before experienced.

The political decision to evacuate the population on Guadeloupe and the ensuing social disruptions exposed the French volcanologists to a much more severe scrutiny than previously experienced by members of this profession. They met the challenge by completely reorganizing their system of volcano observatories, as well as increasing their activity in fundamental research in volcanology.

In recognition of this recent reorganization and of the associated modernization of volcano observatories on Guadeloupe and Martinique, the French government invited representatives of volcano observatories and institutions from all over the world to meet February 18-21, 1981. The main objective of the meeting was to establish or improve ties between people who either have direct responsibility for volcano monitoring in their respective countries or are in some way involved in volcano monitoring and serve as advisers to public authorities. In addition to the host country, France, other countries represented were Costa Rica, Iceland, Indonesia, Italy, Japan, Portugal, Mexico and the U.S.A.

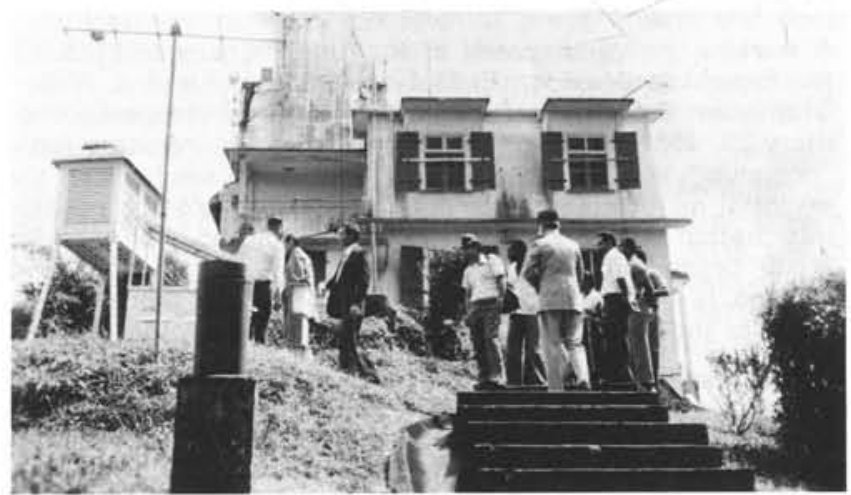

Volcano observatory at Mt. Pelee, Martinique, during WOVO meeting, February, 1981 
After much discussion and exchange of information, the meeting resulted in the establishment of a formal organization, the World Organization of Volcano Observatories (WOVO). As its name implies, WOVO is concerned exclusively with volcano observatories and volcano monitoring, so that its activities do not duplicate those of existing international organizations, such as the International Association of Volcanology and Chemistry of the Earth's Interior (IAVCEI), which deals with the entire field of volcanology. The principal objectives of this new organization are:

- To create or improve ties between observatories and institutions directly involved in monitoring volcanoes;

- To facilitate an exchange of views and experience by convening periodic, perhaps annual meetings;

- To maintain an up-to-date inventory of instrumentation and manpower, which could be made available to any of the member institutions if a situation arises that requires scientific reinforcement;

- To promote funding from international organizations, which could help defray travel and related expenses of scientific reinforcement teams.

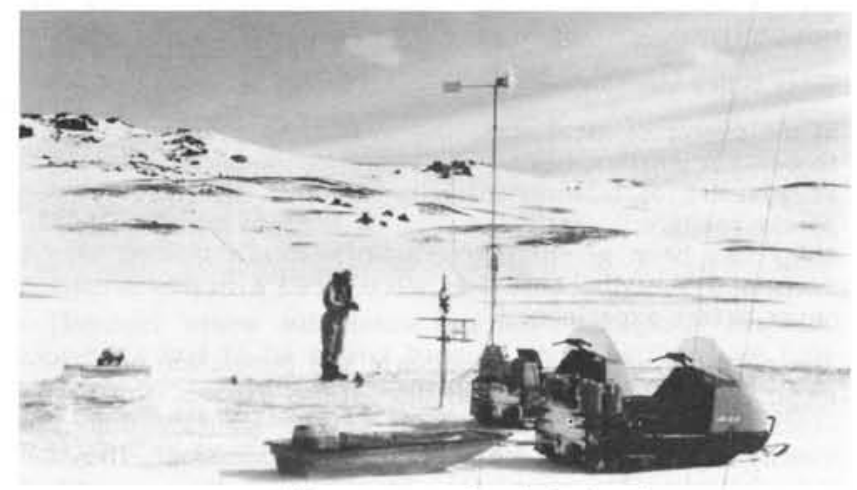

Tiltmeter station in Iceland

An executive board was elected consisting of: Gudmundur E. Sigvaldason, President (Iceland); Robert I. Tilling (U.S.A.); I. Yokoyama (Japan); and J.L. Le Mouel (France). Ecuador, New Zealand, the Philippines, and Tobago and Trinidad expressed an interest in participating in the organization. At the Guadeloupe meeting it was decided that any country could join the organization as a founding member until the next meeting (Iceland, August 1981) planned in connection with the IAVCEI/IAGC meeting on the Generation of Major Basalt Types. Two working groups were also established at the February meeting in Guadeloupe, one on monitoring strategy and the other on an "adequate minimum" volcano observatory.

\section{"Adequate Minimum" Volcano Observatory}

A working group composed of R. Tilling, Chairman (U.S.A.); M. Espendola (Mexico); E. Malavassi (Costa Rica); L. Villari (Italy); and J.P. Viode (France) met at Guadeloupe on February 20,1981 , to discuss informally the requirements for a "minimum" volcano observatory, one which would have the essential monitoring equipment and staff to provide reliable information on the state of an active volcano. The working group began with the premise that any monitoring of a volcano is better than none at all, and then proceeded to consider the concept of an "adequate minimum" observatory.

It was unanimously agreed that continuously recording monitoring systems are absolutely essential for timely volcanic hazard warnings. The following were determined to be the adequate minimum for such systems:

- A seismic network of three stations (short-period vertical seismometers, associated radio-link telemetry, and recording systems) to locate the foci of seismic activity. A simple "tremor" or "seismic" alarm system is also an essential component, so that the observatory staff can be alerted even while at home during the night. An additional few hours'

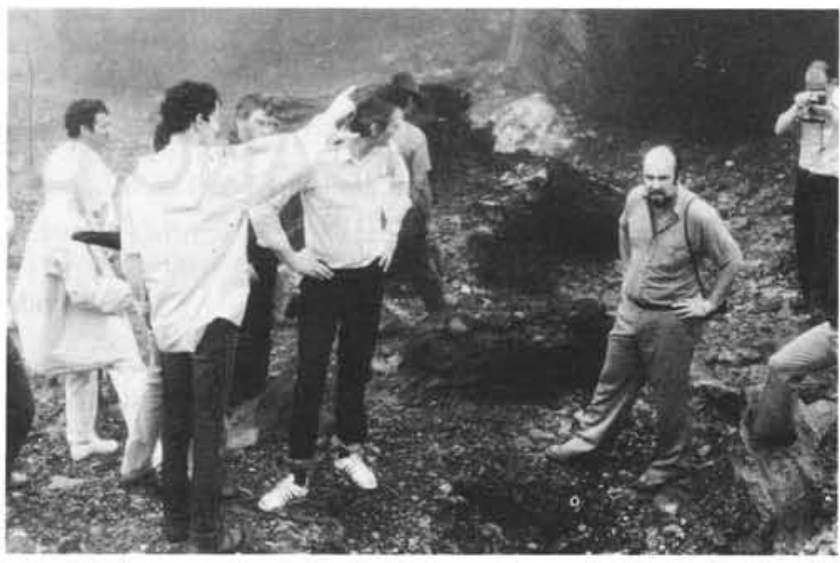

Discussions on slopes of Soufrière Volcano, Guadeloupe

advance notice of possible impending activity could result in significant reduction of casualties and damage.

- A continuously recording tiltmeter (two components) with associated radio-link telemetry should have at least one non-electric tilt measurement array ("dry tilt", water tube, etc.) to serve as check and calibration.

Ideally the following activities should also be undertaken:

- Periodic re-occupation of a network of "dry tilt" stations;

- A modest trilateration (geodimeter) network and a few levelling lines to permit the establishment of bench marks and initial baseline measurements;

- Observations of physical changes in the vicinity of the volcano, e.g. appearance of new fumaroles and/or changes in known fumarolic areas, ground cracking, minor landslides, and other surface indicators of instability; unaccountable changes or damage to vegetation;

- Collection of information resources, documentation, manuals for instruments or monitoring techniques;

- A study of historical records to ascertain historic eruptive pattern; geological mapping and other studies to improve understanding of prehistoric activity.

The working group also considered the problem of getting adequate minimum staff to effectively operate the observatory. They concluded that an observatory should consist of:

- Two geoscientists - one specializing in geophysics/seismology and another specializing in geology/geodesy.

- One electronics engineer or technician.

- Two general-purpose physical science technicians.

\section{Monitoring Strategy}

The monitoring strategy working group, composed of L.A. Mendes Victor, Chairman (Portugal), J.L. Cheminee (France), A. Sudradjat (Indonesia), and I. Yokoyama (Japan), met February 20, 1981, to define a general strategy for monitoring regions where a large number of volcanic events have occurred in historical times. They also set guidelines for institutional cooperation within a country to perform special tasks, so that appropriate measures could be taken to strengthen observational systems and promote fundamental research work on volcanic prediction.

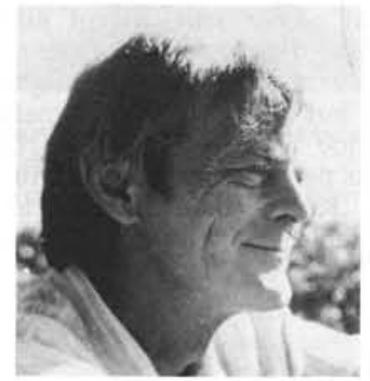

\section{ABOUT THE AUTHOR:}

\section{Dr. Gudmundur E. Sigvaldason}

has been the director of the Nordic Volcanological Institute since 1973. Prior to this, he served as an expert to a geothermal project in El Salvador and Nicaragua and has been a research associate at the University of Iceland working on the geochemistry of geothermal areas and studying active volcanoes. 